\title{
Structural and Behavior Changes of Herbaceous and Hardwood Biomass during Steam Explosion Pretreatment and Enzymatic Hydrolysis
}

\author{
Wen-Chao Li, ${ }^{\text {a }}$ Lin-Jie Han, ${ }^{\mathrm{a}}$ Tai-Bing Peng, ${ }^{\mathrm{a}}$ Yan-Yan Xie, ${ }^{\mathrm{a}}$ Yang Zou, ${ }^{\mathrm{b}}$ Liang-Zhi Li, ${ }^{\mathrm{c}}$ \\ Shi-Ru Jia, ${ }^{\mathrm{a}}$ and Cheng Zhong ${ }^{\mathrm{a}, *}$
}

\begin{abstract}
Steam explosion (SE) was used to pretreat rice straw (RS) and Caragana korshinskii Kom. (CKK). Enzymatic hydrolysis of pretreated RS and CKK, and a pure cellulose (bacterial cellulose, BC) were performed and compared. The characteristics and changes of different substrates during pretreatment and enzymatic hydrolysis were observed. After SE pretreatment, the hemicellulose content of RS and CKK was decreased from $21.7 \%$ to $4.9 \%$ and $17.9 \%$ to $6.2 \%$, respectively. The cellulose percent of RS and CKK was increased to $45.1 \%$ and $38.4 \%$, and the enzymatic hydrolysis conversion of cellulose was increased 1.1 times and 0.9 times, respectively. Although the composition and enzymatic yield of different substrates varied, their enzymatic hydrolysis rates showed a similar declining trend during enzymatic hydrolysis. The adsorption capacities of substrates on the enzyme were increased by pretreatment. The enzymatic hydrolysis efficiency was closely related to the enzyme adsorption capacities of substrates at the initial stage $(1 \mathrm{~h})$. The BC and SE pretreated RS first adsorbed and subsequently desorbed the enzyme, while the untreated RS and CKK had weak adsorption capacity and formed irreversible adsorption with the enzyme. The changes in crystallinity after enzymatic hydrolysis suggested that there was no direct correlation between the crystallinity and digestibility of cellulose.
\end{abstract}

Keywords: Steam explosion; Biomass heterogeneity; Enzymatic hydrolysis; Cellulose crystallinity

Contact information: a: Key Laboratory of Industrial Fermentation Microbiology, Ministry of Education, School of Biotechnology, Tianjin University of Science and Technology, Tianjin, 300457, P. R. China;

b: Tianjin Jialihe Livestock Group Co., Ltd, Jinwei Road, Beichen District, Tianjin 300402, P. R. China; c: School of Chemistry, Biology, and Material Engineering, Suzhou University of Science and Technology, Suzhou, 215009, P. R. China; *Corresponding author: chzhong.tju@gmail.com

\section{INTRODUCTION}

Bioconversion of lignocellulosic biomass to chemicals and fuels has been attracting attention due to the current concerns over food shortages, the energy crisis, and environmental pollutions (Ragauskas et al. 2006; Li et al. 2018). Lignocellulosic biomass is an abundant and renewable resource, which is mainly composed of cellulose, hemicellulose, and lignin. It can be obtained from energy crops, forest residues, agricultural residues, waste paper, and other materials (Morikawa et al. 2014; Weerasai et al. 2014). The processes involved in the bioconversion of lignocellulosic biomass are pretreatment and enzymatic hydrolysis of cellulose and hemicelluloses into fermentable sugars (Ungurean et al. 2014; Bernal-Lugo et al. 2019; Jiang et al. 2019). Pretreatment and enzymatic hydrolysis are complicated processes. The structural features of lignocellulosic 
biomass include chemical composition, microstructure, and crystallinity, which are known to affect pretreatment and digestibility of cellulose to enzymatic hydrolysis (Ioelovich and Morag 2011; Meng and Ragauskas 2014; Jiang et al. 2016; Li et al. 2017; Lai et al. 2018). However, the mechanism of the enzymatic breakdown of lignocellulosic biomass is still not completely clear.

The diversity of biomass types (termed as "biomass heterogeneity") leads to differences in digestibility among these feedstocks. The heterogeneity is caused by the different chemical compositions, cell wall microstructures, and crystallinity of cellulose, which results in different efficiencies of enzymatic hydrolysis (Mood et al. 2013; Chen and Liu 2015; Huang et al. 2018). The compact surrounded structure formed by hemicellulose and lignin makes the lignocellulosic biomass much more difficult to hydrolyze (Jurado et al. 2009). Therefore, it is necessary to pretreat these feedstocks to improve the enzymatic digestibility of cellulose by altering or removing the structure of lignin or hemicellulose. Steam explosion (SE) pretreatment is a low-cost and effective method to improve the enzymatic hydrolysis of hardwood and herbaceous lignocellulose (Singh et al. 2015). No additional chemical reagent is required for steam explosion pretreatment, and it can alter the chemical compositions and physical structures of lignocellulose, which enhances the enzymatic hydrolysis efficiency (Kumar et al. 2009). However, the influence of biomass heterogeneity during the pretreatment and enzymatic hydrolysis needs further clarification. For example, the cellulose crystallinity generally hinders enzymatic hydrolysis (Mittal et al. 2011). Nevertheless, the enzymatic hydrolysis of bacterial cellulose (BC) with high crystallinity (91\%) is easier than that of rice straw (RS, crystallinity 60\%) and Caragana korshinskii Kom. (CKK, crystallinity 66\%). The adsorption capacity of different substrates for the enzyme is also diverse due to their unique structures and compositions. The relationship between the enzyme adsorption and the enzymatic hydrolysis yield is still not very clear. Thus, the investigation of this study will help us to shed light on the enzymatic hydrolysis process of lignocellulosic biomass.

In this experiment, the physical and chemical characteristics of different cellulose substrates and their structural changes during pretreatment and the enzymatic hydrolysis process were compared. The $\mathrm{BC}$, RS, and CKK were selected as the representatives of microbial cellulose, herbaceous biomass, and woody biomass, respectively. BC is synthesized by microorganisms (such as Gluconacetobacter, Achromobacter, Aerobacter, and Agrobacterium) with high purity and high crystallinity (Krishnamachari et al. 2011). RS is an abundant agricultural waste that has been researched as a possible alternative to fossil fuels (Chen et al. 2011; Weerasai et al. 2014). CKK is a perennial woody species that is mainly distributed in the arid and semi-arid regions for conserving soil and water resources. The shrubs of CKK must be harvested every 3 years to make them flourish (Wang et al. 2012; Zhong et al. 2014). Woody biomass is a recalcitrant feedstock and requires more severe pretreatment than herbaceous lignocellulose (Zhu and Pan 2010; Zhao et al. 2012). The SE pretreatment of RS and CKK as well as enzymatic hydrolysis of various types of substrates was performed in this study. The chemical composition of the BC, RS, CKK, and SE pretreated RS and SE pretreated CKK were measured. The glucose and xylose yield from enzymatic hydrolysis of different cellulose substrates were analyzed, and the free enzymes in their hydrolytic supernatant were determined. Scanning electron microscopy (SEM), Fourier transform infrared spectroscopy (FTIR), and X-ray diffraction (XRD) were used to characterize the microtopography, chemical structure, and cellulose 
crystalline structure of untreated and SE pretreated substrates before and after enzymatic hydrolysis.

The goal of this work is to deepen understanding of the changes of herbaceous and hardwood biomass during the pretreatment, as well as the relationship between enzymatic hydrolysis and adsorption of enzymes. The conclusion of this study could be used as the foundation to further improve and optimize the method for biomass pretreatment and to improve the efficiency of enzymatic hydrolysis.

\section{EXPERIMENTAL}

\section{Materials}

RS was harvested from Xintian county in Hunan province, China. CKK was obtained from Liangcheng county in Inner Mongolia, China. These feedstocks were airdried, passed through a screen of $2 \times 2 \mathrm{~cm}^{2}$, and stored at the sealed plastic bag at room temperature. BC was secreted by Gluconacebactor xylinus (CGMCC NO. 2955) and obtained from the laboratory (Zhong et al. 2013). Cellulast 1.5L and xylanase were purchased from Sigma (Shanghai, China). $\beta$-glucosidase was obtained from Youtell Biochemical Co., Ltd (Shanghai, China). All other chemicals were analytical grade and obtained from commercial sources.

\section{Methods}

SE pretreatment

The SE pretreatment was performed in QBS-200B steam explosion equipment (Hebi, Henan Province, China). First, $200 \mathrm{~g}$ of RS or CKK were loaded into the highpressure reactor $(5 \mathrm{~L})$, and high-pressure steam was imported to reach the desired pressure $(2.2 \mathrm{MPa})$. When the pretreatment time was achieved at $5 \mathrm{~min}$, the ball valve was opened immediately, and the steam was released suddenly to the atmospheric pressure. The pretreated sample was collected and washed until the filtrate $\mathrm{pH}$ was 7.0. The $\mathrm{BC}$, pretreated RS and CKK were oven-dried at $40^{\circ} \mathrm{C}$ until the weight was constant. The sample was milled by a beater pulverizer and screened through a square mesh $0.85 \times 0.85 \mathrm{~mm}^{2}$ for further experiments.

\section{Composition analysis}

Composition analysis was carried out according to the National Renewable Energy Laboratory (NREL) standard protocol (Sluiter et al. 2012). Glucose and xylose were detected by high-performance liquid chromatography (HPLC) using a refractive index detector. The column used was the Aminex HPX-87H (Bio-Rad, Hercules, CA, USA). The temperature of the column was maintained at $65^{\circ} \mathrm{C}$, and $0.6 \mathrm{~mL} / \mathrm{min}$ of $5 \mathrm{mM} \mathrm{H}_{2} \mathrm{SO}_{4}$ was used as a mobile phase.

\section{Enzymatic hydrolysis}

Enzymatic hydrolysis of samples was conducted in $100 \mathrm{~mL}$ Erlenmeyer flasks with $1 \%$ glucan loading and a final working weight of $20 \mathrm{~g}$ (Resch et al. 2015). The enzymes were loaded at $15 \mathrm{FPU} / \mathrm{g}$ cellulose of Celluclast $1.5 \mathrm{~L}, 11 \mathrm{mg}$ protein/g cellulose of $\beta$ glucosidase, and $8 \mathrm{mg}$ protein/g cellulose of xylanase. The enzymatic hydrolysis was conducted at $50^{\circ} \mathrm{C}, \mathrm{pH} 4.8$, and $200 \mathrm{rpm}$ for $72 \mathrm{~h}$. The samples were centrifuged $(12,000$ 
rpm, $5 \mathrm{~min}$ ) and filtered with a $0.22 \mu \mathrm{m}$ membrane filter. The concentration of protein in the hydrolytic supernatant was determined by the Bradford method to estimate the amount of adsorbed enzyme in the solid residual during the enzymatic hydrolysis process (Bradford 1976).

SEM

All samples were sputter-coated with platinum and imaged with a scanning electron microscope (JSM-6380LV, JEOL Ltd, Tokyo, Japan).

$X R D$

The XRD patterns were obtained using an x-ray diffractometer (D/max-2500, Rigaku Corporation, Tokyo, Japan) in the $2 \theta$ range of 10 to $40^{\circ}$. Samples were sieved with an 80 -mesh screen and positioned on a quartz sample holder. The scan speed was $4^{\circ} \mathrm{min}^{-1}$ with a step size of $0.02^{\circ}$. The crystalline index of the samples was calculated based on the peak height method following Eq. 1 (Cao and Tan 2005),

$$
\operatorname{CrI}(\%)=\left(I_{002}-I_{\mathrm{am}}\right) / I_{002} \times 100 \%
$$

where $I_{002}$ is the peak height at $2 \theta=22.6^{\circ}$ of the lattice planes (002) and $I_{\mathrm{am}}$ is the peak height at $2 \theta=19.0^{\circ}$ of the amorphous phases.

FTIR

The samples were mixed with $\mathrm{KBr}$ and pressed into a plate using a tableting machine. The IR spectrum was recorded at a range of 4000 to $400 \mathrm{~cm}^{-1}$ wavenumbers with 16 scans and a resolution of $4 \mathrm{~cm}^{-1}$ (TENSOR 27, Bruker, Karlsruhe, Germany).

\section{RESULTS AND DISCUSSION}

\section{Composition Analysis}

The chemical composition of $\mathrm{BC}$, untreated and $\mathrm{SE}$ pretreated lignocellulose is shown in Table 1.

Table 1. Chemical Composition of BC, Untreated, and SE Pretreated Samples

\begin{tabular}{|c|c|c|c|c|}
\hline \multirow{2}{*}{ Samples } & \multicolumn{4}{|c|}{ Component content (Mean \pm SD, \%) } \\
\cline { 2 - 5 } & Cellulose & Hemicellulose & Lignin (AIL) & Ash \\
\hline BC & $>99$ & 0 & 0 & 0 \\
\hline Untreated RS & $33.3 \pm 0.6$ & $21.7 \pm 1.6$ & $5.7 \pm 1.2$ & $14.1 \pm 1.5$ \\
\hline SE pretreated RS & $45.1 \pm 0.6$ & $4.9 \pm 3.7$ & $28.2 \pm 3.3$ & $13.8 \pm 0.7$ \\
\hline Untreated CKK & $30.6 \pm 1.9$ & $17.9 \pm 0.6$ & $23.7 \pm 0.7$ & $3.3 \pm 2.1$ \\
\hline SE pretreated CKK & $38.4 \pm 2.0$ & $6.2 \pm 4.5$ & $41.5 \pm 1.5$ & $2.9 \pm 1.0$ \\
\hline $\begin{array}{l}\text { BC: Bacterial cellulose; RS: Rice straw; CKK: Caragana korshinskii Kom.; } \\
\text { SE: Steam explosion. }\end{array}$
\end{tabular}

The BC, RS, and CKK had very different chemical compositions. The cellulose content of BC was more than $99 \%$, while the cellulose contents of untreated RS and CKK were $33.3 \%$ and $30.6 \%$, respectively. There was a large amount of lignin and hemicellulose 
in the RS and CKK. These components form a dense, three-dimensional structure with cellulose, which limits the enzymatic digestibility of cellulose. When RS and CKK were subjected to SE pretreatment, most hemicelluloses and part of the ash content were removed (mainly cellulose and lignin were left). The hemicellulose content of RS and CKK after SE pretreatment was decreased from $21.7 \%$ to $4.9 \%$ and $17.9 \%$ to $6.2 \%$, respectively. The cellulose content of RS and CKK was increased to $45.1 \%$ and $38.4 \%$, respectively. The results indicated that the SE pretreatment could increase the percent of cellulose and decrease the hemicellulose and ash for the different lignocelluloses.

\section{Enzymatic Hydrolysis}

The $\mathrm{BC}$, as well as the untreated and SE pretreated samples were enzymatically hydrolyzed using commercial Cellulast $1.5 \mathrm{~L}$ coupled with $\beta$-glucosidase and xylanase at $50{ }^{\circ} \mathrm{C}$ for $72 \mathrm{~h}$. Glucose and xylose yields of these substrates during enzymatic hydrolysis are shown in Fig. 1. The BC had the highest enzymatic hydrolysis rate and yield. In all cases, the enzymatic conversion during the first $24 \mathrm{~h}$ was quick and slowed down gradually. The glucose yield of $\mathrm{BC}$ reached $85.9 \%$ at $24 \mathrm{~h}$ and continued to increase to $93.1 \%$ at 72 h. However, only $40.0 \%$ and $23.5 \%$ glucose yield were observed for the untreated RS and CKK after $72 \mathrm{~h}$ of enzymatic hydrolysis, respectively. The SE pretreatment increased the glucose and xylose yields of RS and CKK. $82.6 \%$ and $45.5 \%$ glucose yield, and $49.7 \%$ and $39.1 \%$ xylose yield were obtained for SE pretreated RS and CKK at $72 \mathrm{~h}$. These results indicated that SE pretreatment could improve glucose and xylose yields of lignocellulosic substrates. The enzymatic hydrolysis yield of RS was higher than CKK regardless of pretreatment. This is consistent with the previous studies that woody biomass had higher lignin content and stronger recalcitrance than herbaceous biomass (Zhu and Pan 2010; Zhao et al. 2012). Combined with the results of the composition analysis, although the compositions of different substrates were diverse, the hydrolysis rate of all substrates during the enzymatic hydrolysis process were gradually reduced. The higher cellulose content led to the higher enzymatic digestibility.
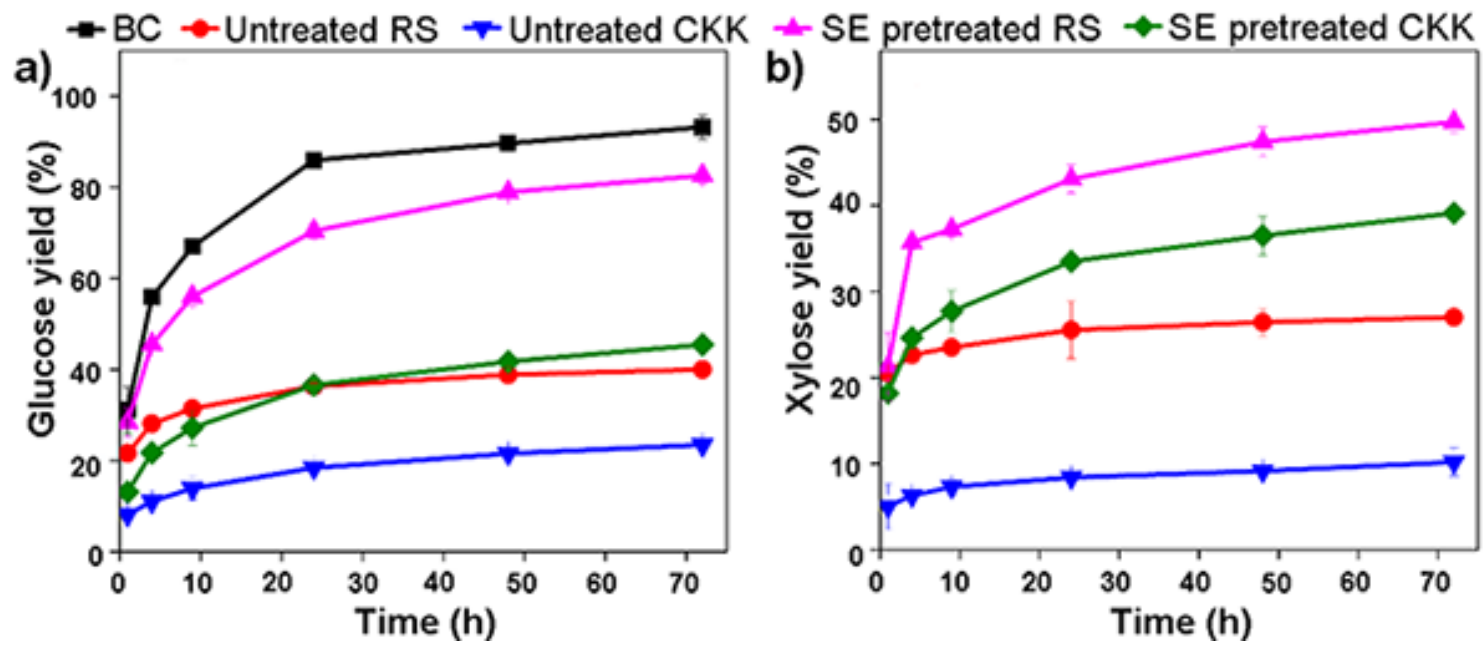

Fig. 1. Glucose and xylose yield of different cellulose substrates during enzymatic hydrolysis; a) glucose yield; b) xylose yield. BC: Bacterial cellulose; RS: Rice straw; CKK: Caragana korshinskii Kom.; SE: Steam explosion 


\section{Enzyme Adsorption}

The purpose of studying enzyme adsorption is to investigate the common features or changes that could be associated with the reduced rates of hydrolysis. The adsorption performance of the enzyme on the substrate was investigated (Palonen et al. 2004). The enzyme in the solution needs to be adsorbed on the substrate first and will then subsequently carry out the enzymatic hydrolysis. Therefore, the amount of free enzymes in the hydrolytic supernatant was measured and subtracted from the initial added enzymes to calculate the portion of adsorbed enzymes. Although adsorption of enzymes during enzymatic hydrolysis of lignocellulose containing lignin has been extensively studied, less results using pure cellulose substrates have been published. Figure 2 showed BC, as well as untreated and pretreated RS and CKK adsorption performances with the enzyme during enzymatic hydrolysis. BC adsorbed $69.8 \%$ of the enzyme during the 1 hour of enzymatic hydrolysis. The untreated RS and CKK only adsorbed $20.7 \%$ and $14.3 \%$ of the enzyme at $1 \mathrm{~h}$, respectively. SE pretreatment effectively improved the adsorption capacity of substrates on the enzyme. The adsorption of the enzyme on the pretreated substrate was increased to $79.7 \%$ (RS) and $48.3 \%$ (CKK) within $1 \mathrm{~h}$. This is most likely because most hemicelluloses were removed, and the surface areas of the substrates were increased (Palonen et al. 2004; Kumar et al. 2009). After the initial rapid adsorption period, the adsorbed enzyme of BC was gradually released into the enzymatic hydrolysis supernatant. As a result, the free enzymes in the supernatant of BC enzymatic hydrolysate was increased to $69.1 \%$ after $24 \mathrm{~h}$ of enzymatic hydrolysis. As for the SE pretreated RS and CKK, the free enzyme in supernatant of SE pretreated CKK was decreased continuously with the processing of enzymatic hydrolysis, while that of SE pretreated RS slightly increased after $1 \mathrm{~h}$ and then remained almost unchanged after $10 \mathrm{~h}$. At the same time, although SE pretreated CKK adsorbed higher enzymes than untreated RS (Fig. 2), its enzymatic yield at $72 \mathrm{~h}$ was only slightly higher than untreated RS (even lower than untreated RS before $24 \mathrm{~h}$ ). This might be due to the fact that the lignin of pretreated lignocellulosic biomass was unproductive and it irreversibly adsorbed the enzyme, and the adsorption of hardwood lignin was different from herbaceous lignin (Tu et al. 2009; Guo et al. 2014).

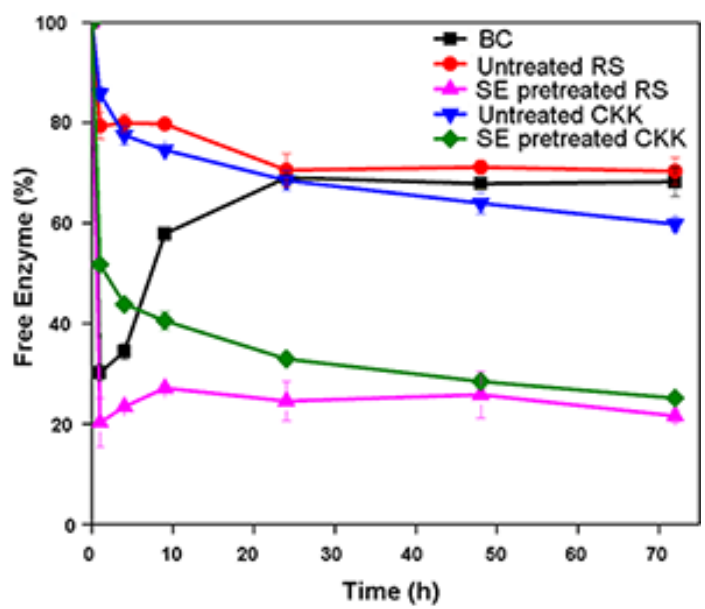

Fig. 2. Enzyme adsorption during the enzymatic hydrolysis of different cellulose substrates. BC: Bacterial cellulose; RS: Rice straw; CKK: Caragana korshinskii Kom.; SE: Steam explosion

It was found that the substrates with high enzymatic hydrolysis yield (BC and SE pretreated RS) would first rapidly adsorb the enzyme and desorb subsequently, while the 
substrates with low enzymatic hydrolysis yield (untreated RS and CKK) had weak adsorption capacity. The time course of enzyme adsorption indicated that BC had both strong enzymes adsorb and desorption ability compared to lignocellulose, which was attributed to the absence of irreversible adsorption of lignin or hemicellulose. It was obviously that BC could be used as substrate for the study of the process of pure cellulose enzymatic hydrolysis, which avoided the interference of lignin or hemicellulose. The evaluated distribution of cellulase during enzymatic hydrolysis can be used to improve the cellulase recycling in further study (Tu et al. 2007; Rodrigues et al. 2014).

\section{SEM Analysis}

The micro-morphology of the untreated and SE pretreated biomass was observed by SEM to examine the apparent changes of substrates during pretreatment. As shown in Fig. 3a-b, rigid and highly ordered fibrils were observed for the untreated RS and CK. The surface of untreated CKK looks rougher than in the untreated RS. The SE treatment would result in morphological changes of RS and CKK. The morphologies of pretreated lignocellulose were quite different from untreated lignocellulose. The cellulose fibers were separated and exposed after SE pretreatment, and the external surface area and porosity were increased (Fig. 3c-d). This could lead to higher susceptibility of attack by enzymes in pretreated lignocellulose. Moreover, many droplets were found on the surface of pretreated samples, which could be from the migration and redeposition of lignin from the cell walls (Donohoe et al. 2010). Compared to the scattered structure of SE pretreated RS (Fig. 3c), the SE pretreated CKK showed a more compact structure (Fig. 3d). These results demonstrated that CKK had a stronger resistibility to SE pretreatment. This was most likely due to large amounts of lignin contained in the CKK.
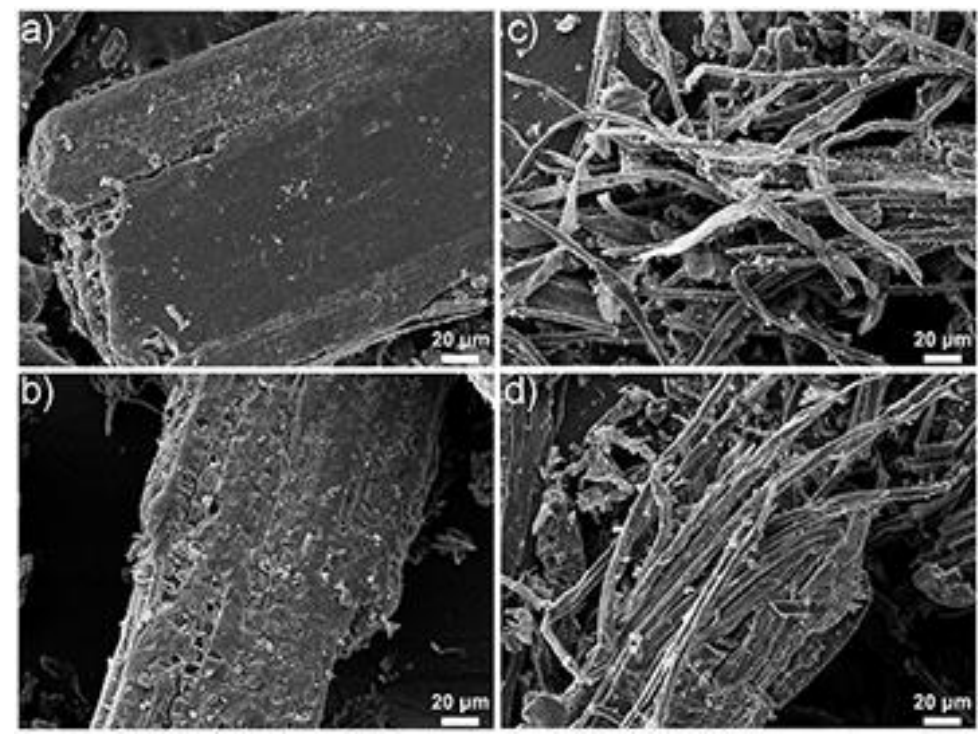

Fig. 3. SEM micrographs of untreated and SE pretreated lignocellulose: a) untreated RS; b) untreated CKK; c) SE pretreated RS; and d) SE pretreated CKK. RS: Rice straw; CKK: Caragana korshinskii Kom.; SE: Steam explosion

To demonstrate the microstructure changes of cellulose substrates during the enzymatic hydrolysis, SEM was employed to observe the solid residues after $0 \mathrm{~h}, 4 \mathrm{~h}, 24$ $\mathrm{h}$, and $72 \mathrm{~h}$ of hydrolysis. Figure $4 \mathrm{a}$ reveals that the surface of $\mathrm{BC}$, compared with freeze- 
dried BC, oven-dried and pulverized BC was more compact and intact (Penttilä et al. 2018). There were many unsmooth pits after $4 \mathrm{~h}$ of enzymatic hydrolysis (Fig. 4b). As the enzymatic hydrolysis proceeded, the monolithic structure was eventually degraded into small particles (Fig. 4c-d). For the SE pretreated RS and CKK, the microfibers were gradually degraded into shorter fibers and continued degradation into small particles (Fig. 4e-1). After $72 \mathrm{~h}$ of enzymatic hydrolysis, the size of the hydrolyzed solid residues of SE pretreated RS (Fig. 4h) was smaller than that of SE pretreated CKK (Fig. 4l). These results suggested that the cellulase could randomly cut the substrate into small pieces during the enzymatic process.
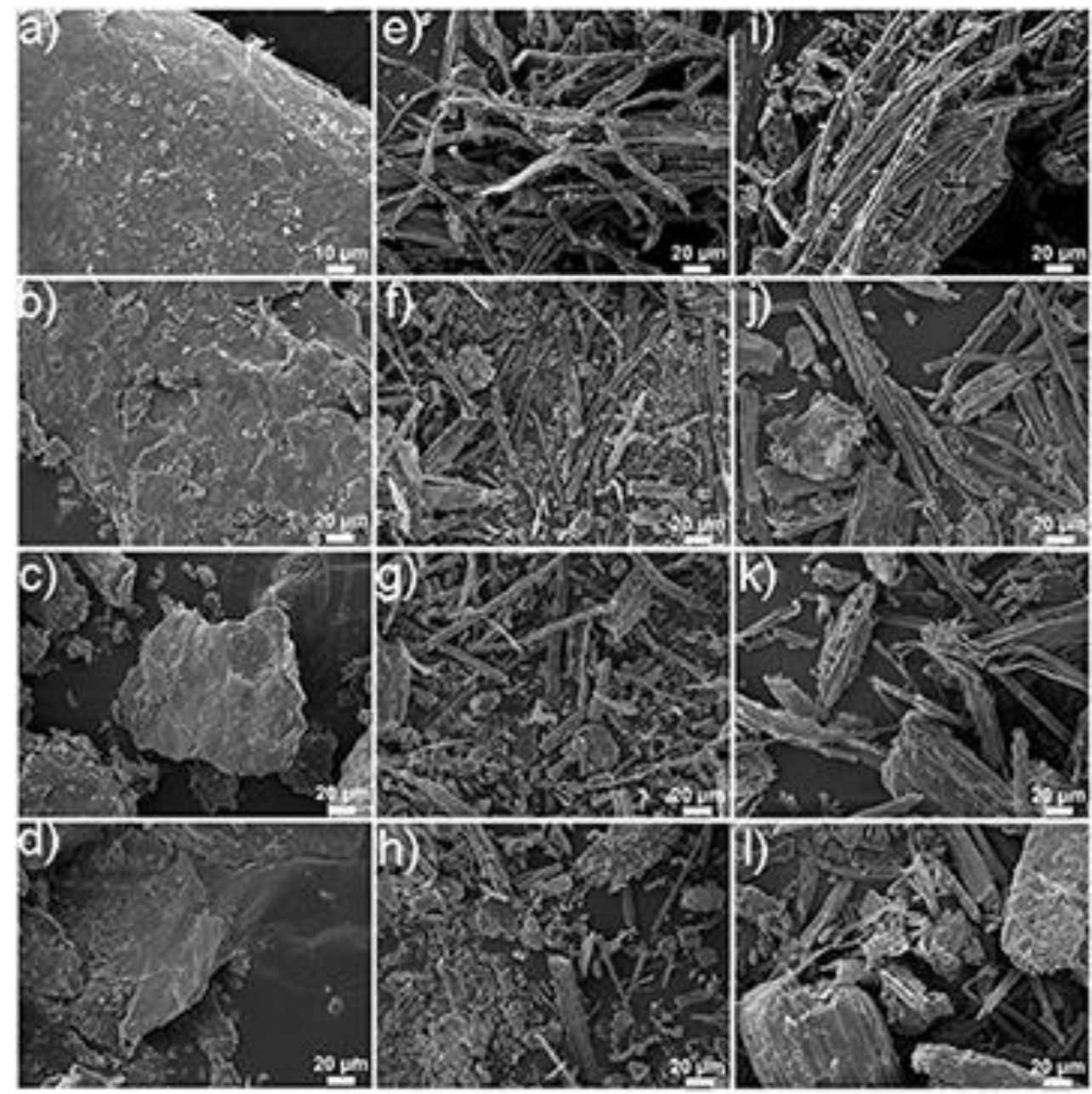

Fig. 4. SEM micrographs of solid residues after $0 \mathrm{~h}, 4 \mathrm{~h}, 24 \mathrm{~h}$ and $72 \mathrm{~h}$ of enzymatic hydrolysis of BC (a-d), SE pretreated RS (e-h), and SE pretreated CKK (i-I), respectively. BC: Bacterial cellulose; RS: Rice straw; CKK: Caragana korshinskii Kom.; SE: Steam explosion

\section{FTIR Analysis}

The chemical structure changes of different cellulose substrates before and after enzymatic hydrolysis were characterized by FTIR (Fig. 5). The peaks at $1058 \mathrm{~cm}^{-1}, 1108$ $\mathrm{cm}^{-1}, 1164 \mathrm{~cm}^{-1}, 1370 \mathrm{~cm}^{-1}$, and $3350 \mathrm{~cm}^{-1}$ were typically related to the special absorption of cellulose (Adapa et al. 2009; Hsu et al. 2010). The peaks at $1058 \mathrm{~cm}^{-1}$ and $1108 \mathrm{~cm}^{-1}$ were assigned to the $\mathrm{C}-\mathrm{O}$ vibration and the $\mathrm{C}-\mathrm{O}-\mathrm{C}$ pyranose ring skeletal vibration. The 
absorption band at $1164 \mathrm{~cm}^{-1}$ was assigned to the antisymmetric bridge $\mathrm{C}-\mathrm{O}-\mathrm{C}$ stretching in cellulose (Silva et al. 2012; Chen et al. 2016). The band at $1370 \mathrm{~cm}^{-1}$ is associated with the $\mathrm{C}-\mathrm{H}$ stretch of cellulose. The peak at $3350 \mathrm{~cm}^{-1}$ was attributed to the $\mathrm{O}-\mathrm{H}$ stretching vibrations of cellulose. The intensity of these peaks in $\mathrm{BC}$ was higher than that in untreated $\mathrm{RS}$ and CKK. This was due to BC being almost pure cellulose, while the cellulose of RS and CKK were encapsulated by hemicellulose and lignin. The absorption peaks in the untreated RS and CKK were like that in the SE pretreated solid, which indicated that the chemical structure of the cellulose in RS and CKK were not disrupted by pretreatment. For the untreated RS and CKK, the FTIR spectra showed two shoulder peaks at $1732 \mathrm{~cm}^{-1}$ and $1245 \mathrm{~cm}^{-1}$, which corresponded to the $\mathrm{C}=\mathrm{O}$ and $\mathrm{C}-\mathrm{O}$ bond stretching of hemicellulose, respectively (Adapa et al. 2009; Hsu et al. 2010). However, the intensity of these two peaks in SE pretreated RS and CKK were much lower. These results confirmed the results that most of the hemicellulose was removed by SE pretreatment, which was obtained in the composition analysis. The absorption peaks at $1512 \mathrm{~cm}^{-1}$ and $1463 \mathrm{~cm}^{-1}$ in the untreated RS and CKK were assigned to the aromatic skeletal vibrations in lignin-like structures (Adapa et al. 2009; Zhou et al. 2011; Monteil-Rivera et al. 2013). After enzymatic hydrolysis, the peaks at $1512 \mathrm{~cm}^{-1}$ and $1463 \mathrm{~cm}^{-1}$ of SE pretreated RS and CKK were increased. The peaks at $1058 \mathrm{~cm}^{-1}, 1108 \mathrm{~cm}^{-1}$, and $1164 \mathrm{~cm}^{-1}$ in BC and SE pretreated RS were decreased, while no noticeable change in the SE pretreated CKK. The results indicated that the cellulose content in the substrate was gradually decreased during the enzymatic hydrolysis, while the lignin content was increased.

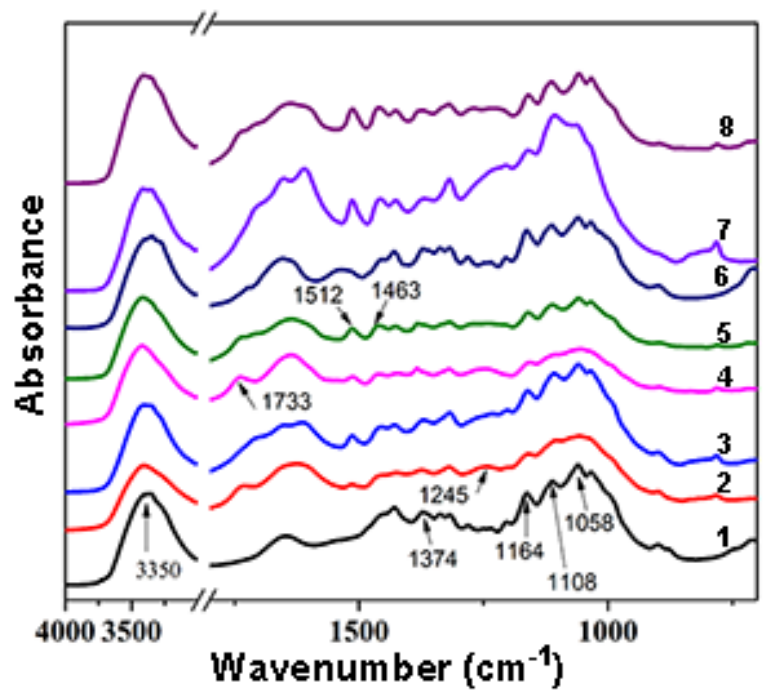

Fig. 5. FTIR spectra of different cellulose substrates before and after enzymatic hydrolysis (line 1, BC; line 2, untreated RS; line 3, SE pretreated RS; line 4, untreated CKK; line 5, SE pretreated CKK; line 6, BC after $24 \mathrm{~h}$ enzymatic hydrolysis; line 7, SE pretreated RS after $72 \mathrm{~h}$ enzymatic hydrolysis; line 8, SE pretreated CKK after $72 \mathrm{~h}$ enzymatic hydrolysis). BC: Bacterial cellulose; RS: Rice straw; CKK: Caragana korshinskii Kom.; SE: Steam explosion

\section{XRD Analysis}

To evaluate the relationship of cellulose crystallinity with the enzymatic hydrolysis, the XRD spectra of different substrates at different time points of the enzymatic hydrolysis process was measured (Fig. 6, Table 2). The diffraction peaks appeared at $2 \theta$ of $14.20^{\circ}$, 
$16.42^{\circ}$, and $22.36^{\circ}$ of $\mathrm{BC}$ represent a typical $(\mathrm{I} \alpha)$ crystalline structure of cellulose. The large diffraction peak at approximately $22.36^{\circ}$ represents the presence of a highly organized 'crystalline' cellulose structure, which was also observed in the XRD spectra of the untreated RS and CKK (Fig. 6b-c). However, this peak in untreated RS and CKK was wider and rounder than in $\mathrm{BC}$ as the presence of hemicellulose and lignin. After SE pretreatment, the peak of RS and CKK at $22.36^{\circ}$ gets sharper and narrower. This reflected the higher crystallinity in SE pretreated RS and CKK. After enzymatic hydrolysis, the hydrolyzed solid showed a similar XRD spectra to that of the initial substrates. As a result, the cellulosic crystal style in hydrolyzed solid residues did not change during enzymatic hydrolysis.
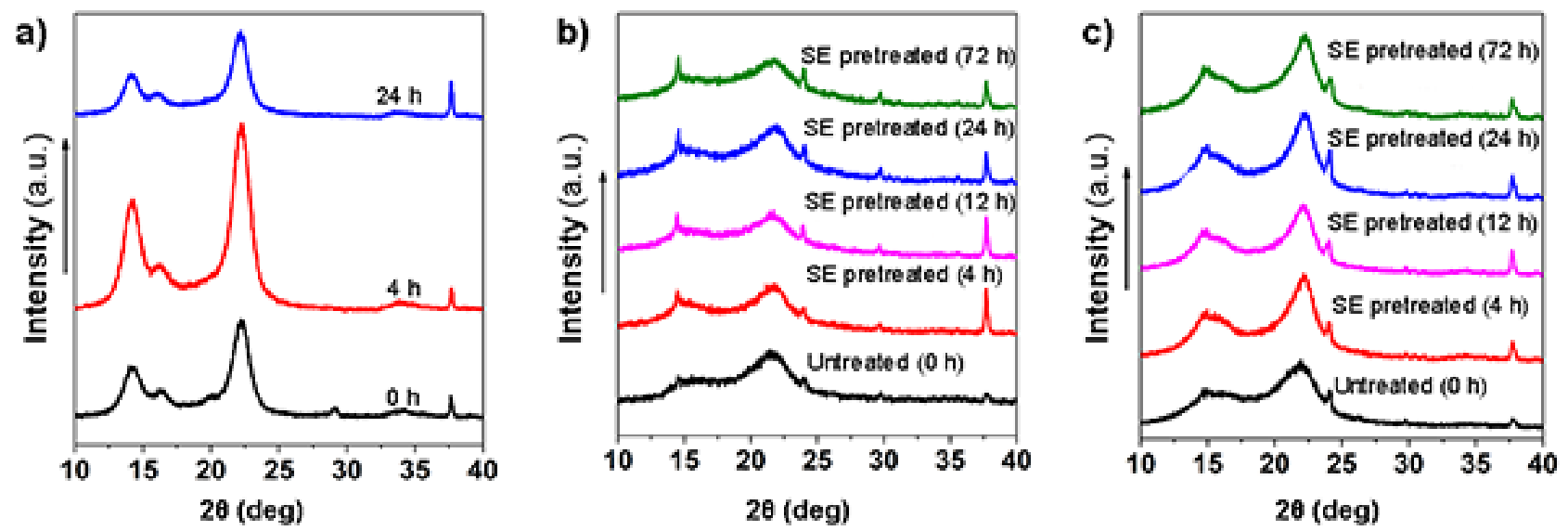

Fig 6. XRD spectra of $B C(a)$, RS (b), and CKK (c) during enzymatic hydrolysis. BC: Bacterial cellulose; RS: Rice straw; CKK: Caragana korshinskii Kom.; SE: Steam explosion

Table 2 shows the $C r I$ that was calculated from the X-ray diffraction patterns. The data demonstrated that there was no direct correlation between crystallinity and enzymatic hydrolysis. The previous studies had shown that the crystallinity would hinder the enzymatic hydrolysis (Mittal et al. 2011). BC used here was regarded as a pure and high crystalline cellulose, and one can easily study the relationship between crystallinity and enzymatic hydrolysis to exclude the influence of lignin and hemicellulose. In this study, the value of $\mathrm{CrI}$ was $91.0 \%, 59.9 \%$, and $65.9 \%$ for $\mathrm{BC}$, untreated RS, and CKK, respectively. $\mathrm{BC}$ has the highest crystallinity in all samples, but its enzymatic hydrolysis yield was the highest as well. After SE pretreatment, the $C r I$ of RS and CKK was increased to $70.3 \%$ and $78.8 \%$, respectively, and the enzymatic hydrolysis was enhanced at the same time. The increase of $\mathrm{CrI}$ for lignocellulose after acid, alkali, or SE pretreatment has also been reported in previous studies (Kapoor et al. 2015; Chen et al. 2016; Lotfi Aski et al. 2018). This might be due to the CrI of lignocellulose being sensitive to other components such as hemicellulose, lignin, and amorphous cellulose domains (Chen et al. 2016). The increase in $\mathrm{CrI}$ could be attributed to the removal of hemicellulose and ash, or the disruption of amorphous cellulose during SE pretreatment. Besides, the $C r I$ of the BC, SE pretreated RS, and SE pretreated CKK did not show any obvious changes during the enzymatic hydrolysis. Mansfield also found there was no discernible difference in the value of $\mathrm{CrI}$ for unbleached Kraft pulp before and after enzymatic hydrolysis (76.5\% and 76.8\% crystalline for the samples before and after enzymatic hydrolysis, respectively) (Mansfield 
et al. 1997). Wang et al. (2010) found CrI only increased by $2 \%$ after 6 days of enzymatic hydrolysis in cotton fibers. This demonstrated that the enzymatic hydrolysis might not preferentially hydrolyze amorphous cellulose. The combined effect of crystallinity and composition was the key to determining the yield of enzymatic hydrolysis (Park et al. 2010; Li et al. 2014).

Table 2. The Crystallinity Index (Crl) of Different Cellulose Substrates

\begin{tabular}{|c|c|c|c|}
\hline & \multicolumn{3}{|c|}{ Crl of Substrates (Mean \pm SD, \%) } \\
\cline { 2 - 4 } & RS & CKK & BC \\
\hline Untreated & $59.9 \pm 1.3$ & $65.9 \pm 4.2$ & $91.0 \pm 0.7$ \\
\hline $\begin{array}{c}\text { SE pretreated } \\
\text { 4 h hydrolysed } \\
\text { sample of SE pretreated }\end{array}$ & $70.3 \pm 2.3$ & $78.8 \pm 1.6$ & N.D. \\
\hline $\begin{array}{c}\text { 24 h hydrolysed } \\
\text { sample of SE pretreated }\end{array}$ & $71.2 \pm 1.3$ & $84.1 \pm 0.7$ & $91.3 \pm 0.9$ \\
\hline $\begin{array}{c}72 \text { h hydrolysed } \\
\text { sample of SE pretreated }\end{array}$ & $71.3 \pm 1.3$ & $79.5 \pm 2.8$ & N.D. \\
\hline $\begin{array}{l}\text { BC: Bacterial cellulose; RS: Rice straw; CKK: Caragana korshinskii Kom.; } \\
\text { SE: Steam explosion. N.D., Not detected. }\end{array}$ & \multicolumn{4}{|c}{} \\
\hline \multicolumn{4}{|c|}{} \\
\hline
\end{tabular}

\section{CONCLUSIONS}

1. Although the composition and enzymatic yield of different substrates varied, their enzymatic hydrolysis rates showed a similar trend during hydrolysis. The enzymatic hydrolysis rates declined with enzymatic hydrolysis. The adsorption efficiency of cellulose to the enzyme was maximized at the initial enzymatic stage.

2. Bacterial cellulose (BC) and rice straw (SE) pretreated rice straw (RS) could firstly adsorb and subsequently desorb the enzyme, while the untreated RS and Caragana korshinskii (CKK) had weak adsorption capacity. Untreated RS and CKK would also form irreversible adsorption with the enzyme.

3. There is no direct correlation between the crystallinity and the enzymatic hydrolysis yield of cellulose in this study. FTIR results showed that the cellulose was continuously released, and lignin was retained in the enzymatic residue during enzymatic hydrolysis.

\section{ACKNOWLEDGMENTS}

This research was funded by the Special Fund for Agro-scientific Research in the Public Interest, Grant No. 201503135-15; the National Natural Science Foundation of China, Grant No. 31470610, 21576212; and the Natural Science Foundation of Tianjin, Grant No. 19PTSYJC00060.

\section{REFERENCES CITED}

Adapa, P., Karunakaran, C., Tabil, L., and Schoenau, G. (2009). "Potential applications of 
infrared and Raman spectromicroscopy for agricultural biomass," Agric. Eng. Int. 11, 1-25. DOI:

Bernal-Lugo, I., Jacinto-Hernandez, C., Gimeno, M., Montiel, C. C., Rivero-Cruz, F., and Velasco, O. (2019). "Highly efficient single-step pretreatment to remove lignin and hemicellulose from softwood," BioResources 14(2), 3567-3577. DOI:

10.15376/biores.14.2.3567-3577

Bradford, M.M. (1976). "A rapid and sensitive method for the quantitation of microgram quantities of protein utilizing the principle of protein-dye binding," Anal. Biochem. 72(s 1-2), 248-254. DOI: 10.1006/abio.1976.9999

Cao, Y., and Tan, H. M. (2005). "Study on crystal structures of enzyme-hydrolyzed cellulosic materials by X-ray diffraction," Enzyme Microb. Tech. 36(2-3), 314-317. DOI: 10.1016/j.enzmictec.2004.09.002

Chen, H. Z., and Liu, Z. H. (2015). "Steam explosion and its combinatorial pretreatment refining technology of plant biomass to bio-based products," Biotech. J. 10(6), 866885. DOI: $10.1002 /$ biot.201400705

Chen, L., Li, J., Lu, M., Guo, X., Zhang, H., and Han, L. (2016). "Integrated chemical and multi-scale structural analyses for the processes of acid pretreatment and enzymatic hydrolysis of corn stover," Carb. Poly. 141, 1-9. DOI: 10.1016/j.carbpol.2015.12.079

Chen, W. H., Pen, B. L., Yu, C. T., and Hwang, W. S. (2011). "Pretreatment efficiency and structural characterization of rice straw by an integrated process of dilute-acid and steam explosion for bioethanol production," Bioresource Technol. 102(3), 2916-2924. DOI: 10.1016/j.biortech.2010.11.052

Donohoe, B., Decker, S., Tucker, M., Himmel, M., and Vinzant, T. (2010). "Visualizing lignin coalescence and migration through maize cell walls following thermochemical pretreatment," Biotechnol. Bioeng. 101(5), 913-925. DOI: 10.1002/bit.21959

Guo, F., Shi, W., Sun, W., Li, X., Wang, F., Zhao, J., and Qu, Y. (2014). " Differences in the adsorption of enzymes onto lignins from diverse types of lignocellulosic biomass and the underlying mechanism," Biotechnol. Biofuels. 7, 1. DOI: 10.1186/1754-68347-38

Hsu, T. C., Guo, G. L., Chen, W. H., and Hwang, W. S. (2010). "Effect of dilute acid pretreatment of rice straw on structural properties and enzymatic hydrolysis," Bioresource Technol. 101(13), 4907-4913. DOI: 10.1016/j.biortech.2009.10.009

Huang, C., Zhao, C., Li, H. L., Xiong, L., Chen, X. F., Luo, M. T., and Chen, X. D. (2018). "Comparison of different pretreatments on the synergistic effect of cellulase and xylanase during the enzymatic hydrolysis of sugarcane bagasse," RSC Advan. 8(54), 30725-30731. DOI: 10.1039/c8ra05047c

Ioelovich, M., and Morag, E. (2011). "Effect of cellulose structure on enzymatic hydrolysis," BioResources 6(3), 2818-2835. DOI: 10.15376/biores.6.3.2818_2835

Jiang, J. X., Wang, J. W., Zhang, X., and Wolcott, M. (2016). "Evaluation of physical structural features on influencing enzymatic hydrolysis efficiency of micronized wood," RSC Advan. 6(105), 103026-103034. DOI: 10.1039/c6ra22371k

Jiang, K. K., Ding, S. J., and Tang, B. P. (2019). "Optimization of dilute $\mathrm{NaOH}$ pretreatment at mild temperatures for monomeric sugar release from sorghum pith using response surface methodology," BioResources 14(2), 3411-3431. DOI: 10.15376/biores.14.2.3411-3431

Jurado, M., Prieto, A., Martinez-Alcala, A., Martinez, A. T., and Martinez, M. J. (2009). 
"Laccase detoxification of steam-exploded wheat straw for second generation bioethanol," Bioresource Technol. 100(24), 6378-6384. DOI:

10.1016/j.biortech.2009.07.049

Kapoor, M., Raj, T., Vijayaraj, M., Chopra, A., Gupta, R. P., Tuli, D. K., and Kumar, R. (2015). "Structural features of dilute acid, steam exploded, and alkali pretreated mustard stalk and their impact on enzymatic hydrolysis," Carb. Poly. 124, 265-273. DOI: 10.1016/j.carbpol.2015.02.044

Krishnamachari, P., Hashaikeh, R., and Tiner, M. (2011). "Modified cellulose morphologies and its composites; SEM and TEM analysis," Micron. 42(8), 751-761. DOI: 10.1016/j.micron.2011.05.001

Kumar, P., Barrett, D. M., Delwiche, M. J., and Stroeve, P. (2009). "Methods for pretreatment of lignocellulosic biomass for efficient hydrolysis and biofuel production," Ind. Eng. Chem. Res. 48(8), 3713-3729. DOI: 10.1021/ie801542g

Lai, C. H., Tu, M. B., Yong, Q., and Yu, S. Y. (2018). "Synergistic effects of pH and organosolv lignin addition on the enzymatic hydrolysis of organosolv-pretreated loblolly pine," RSC Advan. 8(25), 13835-13841. DOI: 10.1039/c8ra00902c

Li, L., Zhou, W.B., Wu, H.W., Yu, Y., Liu, F., and Zhu, D.W. (2014). "Relationship between crystallinity index and enzymatic hydrolysis performance of celluloses separated from aquatic and terrestrial plant materials," BioResources 9(3), 3993-4005. DOI: 10.15376/biores.9.3.3993-4005

Li, W. C., Li, X., Qin, L., Zhu, J. Q., Han, X., Li, B. Z., and Yuan, Y. J. (2017). "Reducing sugar loss in enzymatic hydrolysis of ethylenediamine pretreated corn stover," Bioresource Technol. 224, 405-410. DOI: 10.1016/j.biortech.2016.11.031

Li, W. C., Li, X., Zhu, J .Q., Qin, L., Li, B. Z., and Yuan, Y. J. (2018). "Improving xylose utilization and ethanol production from dry dilute acid pretreated corn stover by twostep and fed-batch fermentation," Energy 157, 877-885. DOI: 10.1016/j.energy.2018.06.002

Lotfi Aski, A., Borghei, A., Zenouzi, A., Ashrafi, N., and Taherzadeh, M. J. (2018). "Effect of steam explosion on the structural modification of rice straw for enhanced biodegradation and biogas production," BioResources 14(1), 22. DOI:

10.15376/biores.14.1.464-485

Mansfield, S. D., Jong, E. D., Stephens, R. S., and Saddler, J. N. (1997). "Physical characterization of enzymatically modified kraft pulp fibers," J. Biotechnol. 57(57), 205-216. DOI: 10.1016/S0168-1656(97)00100-4

Meng, X., and Ragauskas, A. J. (2014). "Recent advances in understanding the role of cellulose accessibility in enzymatic hydrolysis of lignocellulosic substrates," Curr. Opin. Biotechnol. 27(6), 150-158. DOI: 10.1016/j.copbio.2014.01.014

Mittal, A., Katahira, R., Himmel, M. E., and Johnson, D. K. (2011). "Effects of alkaline or liquid-ammonia treatment on crystalline cellulose: Changes in crystalline structure and effects on enzymatic digestibility," Biotechnol. Biofuels 4(1), 41. DOI: 10.1186/1754-6834-4-41

Monteil-Rivera, F., Phuong, M., Ye, M.W., Halasz, A., and Hawari, J. (2013). "Isolation and characterization of herbaceous lignins for applications in biomaterials," Ind. Crops Prod. 41(1), 356-364. DOI: 10.1016/j.indcrop.2012.04.049

Mood, S. H., Golfeshan, A. H., Tabatabaei, M., Jouzani, G. S., Najafi, G., Gholami, M., and Ardjmand, M. (2013). "Lignocellulosic biomass to bioethanol, a comprehensive review with a focus on pretreatment," Renew. Sust. Energ. Rev. 27(6), 77-93. DOI: 


\subsection{6/j.rser.2013.06.033}

Morikawa, Y., Zhao, X. B., and Liu, D. H. (2014). "Biological co-production of ethanol and biodiesel from wheat straw: A case of dilute acid pretreatment," RSC Advan. 4(71), 37878-37888. DOI: $10.1039 / \mathrm{c} 4 \mathrm{ra} 07251 \mathrm{k}$

Palonen, H., Tjerneld, F., Zacchi, G., and Tenkanen, M. (2004). "Adsorption of trichoderma reesei CBH I and EG II and their catalytic domains on steam pretreated softwood and isolated lignin," J. Biotechnol. 107(1), 65-72. DOI:

10.1016/j.jbiotec.2003.09.011

Park, S., Baker, J. O., Himmel, M. E., Parilla, P. A., and Johnson, D. K. (2010). "Cellulose crystallinity index: measurement techniques and their impact on interpreting cellulase performance," Biotechnol. Biofuels 3(1), 1. DOI: 10.1186/17546834-3-10

Penttilä, P. A., Imai, T., Hemming, J., Willför, S., and Sugiyama, J. (2018). " Enzymatic hydrolysis of biomimetic bacterial cellulose-hemicellulose composites," Carbohydr. Polym. 190, 95-102. DOI: 10.1016/j.carbpol.2018.02.051

Ragauskas, A. J., Williams, C. K., Davison, B. H., Britovsek, G., Cairney, J., Eckert, C. A., Frederick, W. J., Jr., Hallett, J. P., Leak, D. J., Liotta, C. L., Mielenz, J. R., Murphy, R., Templer, R., and Tschaplinski, T. (2006). "The path forward for biofuels and biomaterials," Science 311(5760), 484-489. DOI: 10.1126/science.1114736

Resch, M. G., Baker, J. O., and Decker, S. R. (2015). Low Solids Enzymatic Saccharification of Lignocellulosic Biomass. Laboratory Analytical Procedure, National Renewable Energy Laboratory Publisher, Golden, CO.

Rodrigues, A. C., Felby, C., and Gama, M. (2014). "Cellulase stability, adsorption/ desorption profiles and recycling during successive cycles of hydrolysis and fermentation of wheat straw," Bioresource Technol. 156, 163-169. DOI: 10.1016/j.biortech.2014.01.019

Silva, M. J., Sanches, A. O., Malmonge, L. F., Medeiros, E. S., Rosa, M. F., McMahan, C. M., and Malmonge, J. A. (2012). "Conductive nanocomposites based on cellulose nanofibrils coated with polyaniline-DBSA via in situ polymerization," Macromol. Symp. 319, 196-202. DOI: 10.1002/masy.201100156

Singh, J., Suhag, M., and Dhaka, A. (2015). "Augmented digestion of lignocellulose by steam explosion, acid and alkaline pretreatment methods: A review," Carb. Poly. 117, 624-631. DOI: 10.1016/j.carbpol.2014.10.012

Sluiter, A., Hames, B., Ruiz, R., Scarlata, C., Sluiter, J., Templeton, D., and Crocker, D. (2012). Determination of Structural Carbohydrates and Lignin in Biomass.

Laboratory Analytical Procedure, National Renewable Energy Laboratory Publisher, Golden, CO.

Tu, M., Chandra, R. P., and Saddler, J. N. (2007). "Recycling cellulases during the hydrolysis of steam exploded and ethanol pretreated Lodgepole pine," Biotechnol. Prog. 23(5), 1130-1137. DOI: 10.1021/bp070129d

Tu, M., Pan, X., and Saddler, J. N. (2009). "Adsorption of cellulase on cellulolytic enzyme lignin from lodgepole pine," J. Agric. Food Chem. 57(17), 7771-7778. DOI: 10.1021/jf901031m

Ungurean, M., Csanadi, Z., Gubicza, L., and Peter, F. (2014). "An integrated process of ionic liquid pretreatment and enzymatic hydrolysis of lignocellulosic biomass with immobilised cellulase," BioResources 9(4), 6100-6116. DOI: 10.15376/biores.9.4.6100-6116 
Wang, K., Yang, H. Y., Yao, X., Sun, R. C., and Jones, G. L. (2012). "Structural characterization of isolated lignins from Caragana korshinskii Kom.," Cell Chem. Technol. 46(3-4), 185-191. DOI:

Wang, L. S., Zhang, Y. Z., Gao, P. J., Shi, D. X., Liu, H. W., and Gao, H. J. (2010). "Changes in the structural properties and rate of hydrolysis of cotton fibers during extended enzymatic hydrolysis," Biotechnol. Bioeng. 93(3), 443-456. DOI: 10.1002/bit.20730

Weerasai, K., Suriyachai, N., Poonsrisawat, A., Arnthong, J., Unrean, P., Laosiripojana, N., and Champreda, V. (2014). "Sequential acid and alkaline pretreatment of rice straw for bioethanol fermentation," BioResources 9(4), 5988-6001. DOI: 10.15376/biores.9.4.5988-6001

Zhao, X. B., Zhang, L. H., and Liu, D. H. (2012). "Biomass recalcitrance. Part I: the chemical compositions and physical structures affecting the enzymatic hydrolysis of lignocellulose," Biofuel. Bioprod. Biores. 6(4), 465-482. DOI: 10.1002/bbb.1331

Zhong, C., Zhang, G. C., Liu, M., Zheng, X. T., Han, P. P., and Jia, S. R. (2013). "Metabolic flux analysis of Gluconacetobacter xylinus for bacterial cellulose production," Appl. Micro. Biotechnol. 97(14), 6189-6199. DOI: 10.1007/s00253-0134908-8

Zhong, C., Zhou, Z., Zhang, Y. M., Jia, S. R., Sun, Z., and Dale, B. E. (2014). "Integrating kinetics with thermodynamics to study the alkaline extraction of protein from Caragana korshinskii Kom.," Biotechnol. Bioeng. 111(9), 1801-1808. DOI: 10.1002/bit.25229

Zhou, G. W., Taylor, G., and Polle, A. (2011). "FTIR-ATR-based prediction and modelling of lignin and energy contents reveals independent intra-specific variation of these traits in bioenergy poplars," Plant Methods 7(1), 1-9. DOI: 10.1186/1746-48117-9

Zhu, J. Y., and Pan, X. J. (2010). "Woody biomass pretreatment for cellulosic ethanol production: Technology and energy consumption evaluation," Bioresource Technol. 101(13), 4992-5002. DOI: 10.1016/j.biortech.2009.11.007

Article submitted: September 17, 2019; Peer review completed: November 23, 2019; Revised version received and accepted: November 30, 2019; Published: December 4, 2019.

DOI: 10.15376/biores.15.1.691-705 